\title{
Effects of Maternal Input on Language in the Absence of Genetic Confounds: Vocabulary Development in Internationally Adopted Children
}

\section{Citation}

Shafto, Carissa L., Joy Geren, and Jesse Snedeker. 2010. Effects of maternal input on language in the absence of genetic confounds: Vocabulary development in internationally adopted children. In CogSci 2010: Proceedings of the 32nd Annual Meeting of the Cognitive Science Society: August 11-14, 2010, Portland, Oregon, ed. Stellan Ohlsson and Richard Catrambone, 2775-2780. Austin, TX: Cognitive Science Society.

\section{Published Version}

http://mindmodeling.org/cogsci2010/papers/0659/index.html

\section{Permanent link}

http://nrs.harvard.edu/urn-3:HUL.InstRepos:9978130

\section{Terms of Use}

This article was downloaded from Harvard University's DASH repository, and is made available under the terms and conditions applicable to Open Access Policy Articles, as set forth at http:// nrs.harvard.edu/urn-3:HUL.InstRepos:dash.current.terms-of-use\#OAP

\section{Share Your Story}

The Harvard community has made this article openly available.

Please share how this access benefits you. Submit a story.

Accessibility 


\title{
Effects of Maternal Input on Language in the Absence of Genetic Confounds: Vocabulary Development in Internationally Adopted Children
}

\author{
Carissa L. Shafto ${ }^{1}$, Joy Celeste Geren ${ }^{2}$, \& Jesse Snedeker ${ }^{2}$ \\ ${ }^{1}$ (carissa.shafto@louisville.edu) Dept. of Psychological and Brain Sciences, University of Louisville, Louisville, KY 40292 \\ 2 (geren@fas.harvard.edu, snedeker@wjh.harvard.edu) Dept. of Psychology, Harvard University, Cambridge, MA 02138
}

\begin{abstract}
Parents provide children with both genes (nature) and linguistic input (nurture). A growing body of research demonstrates that individual differences in children's language are correlated with differences in parental speech. Although this suggests a causal link between parental input and the pace of language development, these correlations could reflect effects of shared genes on language, rather than a causal link between input and outcome. We explored effects of maternal input on English vocabulary development in internationally-adopted (IA) children-a population with no genetic confound. IA preschoolers demonstrated some of the same correlations with input as in previous studies; specifically, measures of input quality were significantly correlated with vocabulary. However, IA infants did not demonstrate this pattern. Differences between the age groups may be related to the pace of acquisition; more rapid vocabulary development in the preschoolers suggests that access to, and children's ability to make use of input, may be a limiting factor for the infants.
\end{abstract}

\section{Introduction}

There is a growing body of research demonstrating that individual differences in children's linguistic abilities are correlated with differences in parental speech (e.g., Hart \& Risley, 1992, 1995; Hoff, 2003b; Zimmerman et al., 2009). While these studies and others strongly suggest that variation in parental language input contributes to variability in language development, such studies have an unavoidable confound: biological parents provide children with linguistic and genetic input. In fact, twin studies consistently find that language skills have moderate to high heritability (Stromswold, 2001) and Plomin and Dale go so far as to say "a case could be made that verbal measures are among the most heritable traits" (2000, p. 39). Rather than a direct causal link between input and outcome, these correlations between parental input and child outcomes could potentially reflect direct effects of shared genes on the verbal abilities of both parties. Here we investigate the role of maternal input in children's vocabulary acquisition when the influence of genetics is absent.

We start by discussing the existing literature on variability in maternal input and evidence for relations between input and child language outcomes. Then we present two experiments with IA children adopted at different ages to explore potential differences in uptake related to different paces of language acquisition. Then we conclude by discussing recent findings on the role of genetics in language development and how our results reconcile the gene-environment confound present in previous studies.

\section{Variability in Maternal Language Input}

An early study of differences in caregiver input (Elardo, Bradley, \& Caldwell, 1977) investigated the home environment and language abilities of 74 typically developing children living in an urban setting. The majority of the children were African-American and one-third were on welfare at the time of the study. Caregiver input was measured via a home environment assessment (the Home Observation for Measurement of the Environment; Caldwell, Heider, \& Kaplan, 1966) and children's language abilities were assessed with the Illinois Test of Psycholinguistic Abilities (Kirk, McCarthy, \& Kirk, 1968). The study found that maternal involvement, maternal responsiveness, and providing appropriate play materials had the strongest correlations with children's language.

This study is part of a growing body of research linking individual differences in caregiver demographics to differences in their speech (e.g., Hart \& Risley, 1992, 1995; Hoff, 2003b). In their seminal paper, Hart and Risley (1992) described the qualitative aspects of parental speech in 40 diverse families. The qualitative aspects of the parents' speech to their children were strongly related to socioeconomic status (SES); parents of higher SES were more verbal and had higher quality verbal interactions with their children. Hoff (2003b) found that mothers' mean length of utterance, number of word types, and number of tokens were each uniquely correlated with SES. Hoff also found that mothers' speech to adults varied with SES (2003a).

More recently Huttenlocher and colleagues examined caregiver speech to young children from 50 ethnically and economically diverse families via home video recordings (Huttenlocher, Vasilyeva, Waterfall, Vevea, \& Hedges, 2007). Data were presented from 5 different time points collected when the target children were between 14 and 30 months old. The authors analyzed the composition of speech, the diversity of speech, and the quantity of speech. The results suggest that caregivers' education levels were significantly predictive of the quantity of spoken language and that this relation was more predictive than family income level. They also found that the complexity and diversity of caregiver speech increased linearly over time, while input quantity remained relatively stable.

\section{Effects of Input on Language Development}

One might expect such significant SES-related differences in maternal speech to affect children's language development; this is precisely what is found (see Whitehurst, 1997 for review). In an early study with middle- 
class mothers Huttenlocher et al. found that the quantity of maternal language spoken significantly correlated with children's vocabulary growth from age 14 to 26 months (Huttenlocher, Haight, Bryk, Seltzer, \& Lyons, 1991).

In a study of 22 mother-child dyads varying in SES HoffGinsberg (1986) found several aspects of mothers' speech to correlate with children's language outcomes during the third year of life. Both functional and structural characteristics of maternal speech were predictive of children's language outcomes (e.g., the average number of noun phrases per utterance in maternal speech was predictive of the same feature in children). Another study by Hoff-Ginsberg (1998) found differences between siblings relating to birth order, though genetic influences are similar among siblings.

More recently, in a study of 33 high-SES families and 30 low-SES families Hoff (2003b) found that maternal mean length of utterance, number of word types, and number of word tokens were each uniquely predictive of children's vocabulary size. SES-related differences in maternal speech mediated children's language development such that children with low-SES mothers heard (on average) less rich language input and consequently had less developed language abilities. This finding is supported by a recent review of the literature on how SES relates to brain development (Hackman \& Farah, 2009). Hackman and Farah reviewed studies of SES effects on neurocognitive development and found the strongest effects of SES on the brain areas associated with language and executive function. ${ }^{1}$

In a more recent study focused on children learning Spanish as a first language, Hurtado and colleagues found that maternal input correlated with children's vocabulary growth from 18 to 24 months (Hurtado, Marchman, \& Fernald, 2008). In addition, speed of word recognition at 24 months was related to quantity of maternal input. The effects of maternal speech on vocabulary size and word recognition speed overlapped considerably, suggesting that these abilities work together in lexical acquisition. Taken together these findings suggest that the observed correlations between parental input and child output may reflect a causal role of the input in language development (see also Weizman \& Snow, 2001).

\section{The Current Study}

The current study extends this work by exploring the effects of maternal input on early vocabulary development in internationally-adopted (IA) children-a population which eliminates genetic confound. We previously demonstrated that early language acquisition in this population shows the same qualitative patterns that characterize typical language development, suggesting that similar learning processes may be at work (Snedeker, Geren, \& Shafto, 2007).

In a more recent study (Snedeker, Geren, \& Shafto, in press) we found that the rate of vocabulary acquisition in IA

\footnotetext{
${ }^{1}$ These findings are preliminary and do not preclude effects of SES on other cognitive domains.
}

infants was explained primarily by chronological age, while the rate of acquisition in IA preschoolers was explained primarily by time spent learning (i.e., months in the U.S.). Additionally, the preschool-aged IA children acquired English significantly faster than the IA infants, suggesting that for children adopted at older ages the developmental patterns in the early stages of English acquisition occur on an accelerated time table. The quantity and nature of language input may be even more critical to the pace of acquisition in older learners. The current study explored this possibility through experiments with children adopted in two distinct age groups.

In Experiment 1 we assessed English vocabulary in IA children adopted during the preschool years. In Experiment 2 we assessed English vocabulary in IA children adopted as infants, who may not learn English at such an accelerated rate due to less advanced cognitive abilities (e.g., memory). We tested two age groups to explore potential differences in the effects of maternal input due to differences in the pace of language development.

\section{Experiment 1}

\section{Method}

Participants Twenty-nine children aged 2;9 to 5;2 years who were adopted from Eastern Europe and China between the ages of $2 ; 5$ and $4 ; 11$ (M: $3 ; 1$ years) and had been in the U.S. for 0.5-6 months (M: 3.4 months) at the first assessment. All children were adopted by monolingual English speakers and were typically developing. ${ }^{2}$

All of the children were adopted into upper-middle class homes, with the majority of mothers having earned graduate or professional degrees $(\mathrm{N}=17)$. The other mothers earned a college degree $(\mathrm{N}=9)$ or attended some college $(\mathrm{N}=3)$.

Materials \& Procedure Parents participated in monthly sessions until their child had been in the U.S. for 6 months; thus each child had 1-6 sessions (total=63). For each session parents completed the Words and Sentences form of the MacArthur-Bates CDI ${ }^{3}$ (CDI-2; Fenson et al., 2006) and recorded a language sample in their home. Families were sent a standard box of toys to use for the language sample, which were an average of 27 minutes long and were transcribed and analyzed using the CLAN program (MacWhinney, 2000).

Measures Once the language samples were transcribed, maternal utterances were coded for quantitative and qualitative features. The maternal input quantity variable was the number of words spoken per minute. Maternal input quality variables included: mean length of utterance (MLU), the number of word types spoken per minute (a measure of input diversity), percentage of utterances that were yes/no

\footnotetext{
${ }^{2}$ According to a parent report.

${ }^{3}$ We validated the use of the CDI-2 with this population in a previous study (Snedeker et al., in press).
} 
questions (Is that your crayon?), percentage of utterances that were wh-questions (What color is that?), and the percentage of utterances that were alternative questions ( $D o$ you want to play with the truck or the car?).

Because children had varying numbers of sessions, the maternal input variables were calculated for each session, and the average values for each variable were used as the predictors for that child. This means that for children with more than one recording session, no particular data point was chosen for use (which could have biased the results), and no data points were represented more than once in the analyses.

\section{Results}

CDI-2 'norms' were calculated using data from a larger study of IA preschoolers $(\mathrm{N}=182)$. Stepwise regressions were conducted on CDI-2 vocabulary score with Time in the U.S. $\left(R^{2}=.54, p<.001\right)$ and Age of Arrival $\left(R^{2}=.03, p<.001\right)$ as predictors. ${ }^{4}$ Results were used to calculate standardized residual scores (SRSs) for vocabulary for the final session of the 29 participants in the current study. Specifically, the SRSs were used as a measure of how different children's reported vocabularies were from their predicted vocabulary. Thus a negative SRS would indicate that a child's reported vocabulary was lower than would be predicted by their Age of Arrival and Time in the U.S.

As a first pass raw correlations were conducted between the maternal input variables and children's SRS (see Table 1). Then step-wise regressions were conducted on children's SRSs using the maternal input variables (averaged across sessions) as predictors. At Step 1 maternal word types per minute was a significant predictor of SRS (adjusted $R^{2}=.56$, $p<.001$; see Figure 1). This suggests mothers with more diverse input had children with higher SRSs; their children exceeded their predicted vocabulary by larger amounts.

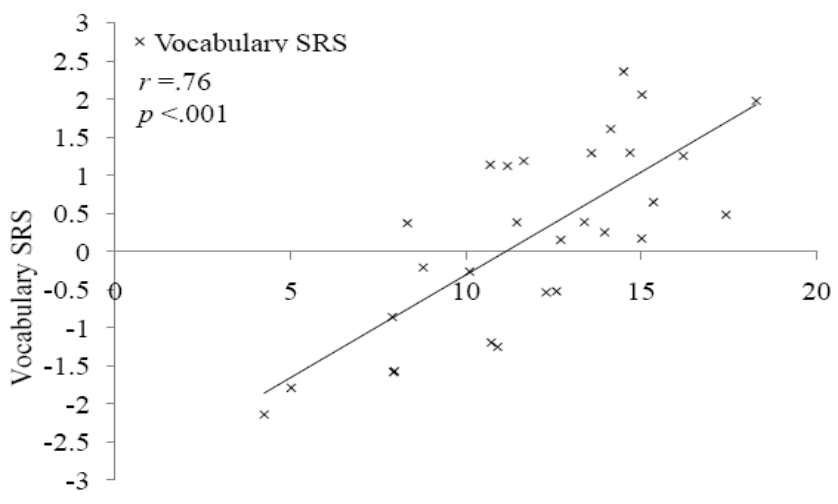

Maternal \# of Word Types Per Minute

Figure 1: IA Preschoolers' Vocabulary SRSs by Diversity of Maternal Input (Experiment 1).

\footnotetext{
${ }^{4}$ Children's Age at Test was not used as a predictor because it was significantly positively correlated with both Age of Arrival $(r=.95$, $p<.001)$ and Time in the U.S. $(r=.19, p<.05)$.
}

Percentage of maternal utterances that were yes/no questions accounted for additional variance (adjusted $\left.R^{2}=.07, p<.001\right)$ suggesting that mothers who asked more yes/no questions had children with higher SRSs. This suggests that higher levels of prompting or engagement facilitated vocabulary growth.

Contrary to previous findings, words per minute (quantity) was not a reliable predictor of SRS (partial $\left.R^{2}=.002, p=.70\right)$. However, this may be due to the high correlation between words per minute and word types per minute (see Table 1).

\section{Experiment 2}

\section{Method}

Participants Seventeen children aged 1;7 to 2;8 who were adopted from China between 8 and 16 months old (M: 12 months) and had been in the U.S. for 7-20 months (M: 15 months) at the first session. All children were adopted by monolingual English speakers and were reported to be typically developing.

All children were adopted into upper-middle class homes, with the majority of mothers having earned graduate or professional degrees $(\mathrm{N}=11)$. The other 6 mothers had all earned a college degree.

Materials \& Procedure Parents completed monthly sessions until their child was 32 months old; thus each child had 1-12 sessions (total=71). Three of the children had some of their language samples recorded with their father instead of their mother. In order to maximize homogeneity across the language samples for all participants, individual sessions that were recorded with the father were excluded from analyses. This left a total of 64 sessions for analyses.

Measures The same as in Experiment 1.

\section{Results}

First CDI-2 'norms' were calculated for the IA infants using data from a larger study of IA infants $(\mathrm{N}=223)$. Step-wise regressions were conducted on CDI-2 vocabulary score with Age at Test $\left(R^{2}=.45, p<.001\right)$ and Age of Arrival $\left(R^{2}=.03\right.$, $p<.001)$ as the predictors. ${ }^{5}$ Results were used to calculate standardized residual scores (SRSs) for the final session of the 17 IA infants in the current study. As a reminder, a child's SRS represents the difference between their reported and predicted English vocabulary (i.e., a $z$ score).

As in Experiment 1, raw correlations were first conducted to determine the relations between the maternal input variables and children's SRSs (see Table 2). Step-wise regressions were then conducted on children's SRSs using maternal input variables (averaged across sessions) as predictors. The percentage of alternative questions

5 Time in the U.S. was not used as a predictor because it was significantly correlated with both Age at Test $(r=.89, p<.001)$ and Age of Arrival $(r=-.28, p<.001)$. 
Table 1: Correlation matrix for Experiment 1 (IA preschoolers).

\begin{tabular}{|c|c|c|c|c|c|c|}
\hline Measure & $\begin{array}{l}\text { Words } \\
\text { per } \\
\text { minute }\end{array}$ & MLU & $\begin{array}{l}\text { Word } \\
\text { types per } \\
\text { minute }\end{array}$ & $\begin{array}{c}\text { Yes/no } \\
\text { questions } \\
\text { (\% of } \\
\text { utterances) }\end{array}$ & $\begin{array}{c}\text { Wh-questions } \\
\text { (\% of } \\
\text { utterances) }\end{array}$ & $\begin{array}{c}\text { Alternative } \\
\text { questions } \\
\text { ( } \% \text { of } \\
\text { utterances) }\end{array}$ \\
\hline Words per minute (word tokens) & -- & & & & & \\
\hline MLU & $.56^{* *}$ & --- & & & & \\
\hline Word types per minute & $.82 * *$ & $.57 * *$ & --- & & & \\
\hline Yes/no questions ( $\%$ of utterances) & .04 & .14 & .06 & --- & & \\
\hline Wh-questions (\% of utterances) & -.29 & -.03 & -.05 & $.50^{* *}$ & --- & \\
\hline Alternative questions (\% of utterances) & -.14 & .02 & -.03 & $.51^{* *}$ & $.65^{* *}$ & --- \\
\hline Standardized residual vocabulary score (SRS) & $.64 * *$ & $.53 * *$ & $.76 * *$ & .33 & .01 & .07 \\
\hline
\end{tabular}

Table 2: Correlation matrix for Experiment 2 (IA infants).

\begin{tabular}{|c|c|c|c|c|c|c|}
\hline Measure & $\begin{array}{l}\text { Words } \\
\text { per } \\
\text { minute }\end{array}$ & MLU & $\begin{array}{l}\text { Word } \\
\text { types per } \\
\text { minute }\end{array}$ & $\begin{array}{c}\text { Yes/no } \\
\text { questions } \\
\text { (\% of } \\
\text { utterances) }\end{array}$ & $\begin{array}{c}\text { Wh-questions } \\
\text { (\% of } \\
\text { utterances) }\end{array}$ & $\begin{array}{c}\text { Alternative } \\
\text { questions } \\
\text { ( } \% \text { of } \\
\text { utterances) }\end{array}$ \\
\hline Words per minute (word tokens) & --- & & & & & \\
\hline MLU & $.61^{* *}$ & --- & & & & \\
\hline Word types per minute & $.57 *$ & $.62 * *$ & --- & & & \\
\hline Yes/no questions (\% of utterances) & -.14 & -.19 & -.09 & --- & & \\
\hline Wh-questions (\% of utterances) & -.12 & .00 & -.26 & $.52 *$ & --- & \\
\hline Alternative questions ( $\%$ of utterances) & $.48^{\mathrm{T}}$ & .41 & .09 & .02 & -.12 & --- \\
\hline Standardized residual vocabulary score (SRS) & .40 & .16 & .18 & 20 & -.21 & $.70 * *$ \\
\hline
\end{tabular}

${ }^{\mathrm{T}} p<.06, * p<.05, * * p<.01$

(e.g., "Do you want to play with the truck or the car?") was the only significant predictor of SRS (adjusted $R^{2}=.47$, $p<.01)$. Mothers who asked more alternative questions had children with higher SRSs - children who exceeded their predicted vocabulary by greater amounts (see Figures 2 and 3).

Contrary to Experiment 1, maternal word types per minute and percentage of yes/no questions were not reliable predictors of SRS (adjusted $R^{2}=-.03, p=.51$; adjusted $R^{2}=-$ $.001 p=.33$, respectively). This suggests that the features of maternal speech that seem to influence English vocabulary growth in IA children adopted as preschoolers might be less influential for IA children adopted as infants. Alternatively, the smaller sample size in the infant group may have made any additional effects of maternal input variables undetectable. ${ }^{6}$ As in Experiment 1, but contrary to previous findings, words per minute (input quantity) was not a reliable predictor of SRS (incremental $R^{2}=.005, p=.72$ ). Unlike in Experiment 1, the raw correlation with words per minute was not significant either (see Table 2). However, the correlation value was moderate (.40), so one possibility is that the effect was suppressed by the variability present in our small sample.

\footnotetext{
${ }^{6}$ For a moderate correlation $(r=.5)$ with power of $80 \%$ a minimum sample size of 28 children is needed.
}

\section{General Discussion}

There were significant relations between some qualitative aspects of maternal input - maternal word types and yes/no questions-and English vocabulary ability for the preschool-aged IA children. This is in accord with previous findings of a positive relation between maternal input and children's vocabulary development. Curiously, the relation between input and outcome differed in the two age groups. This difference occurred despite the fact that both age groups were adopted into families with similar SES (high), and thus were like the professional families from Hoff (2003b) who received quite rich language input.

One possible explanation for the difference between age groups is that perhaps older children are more sensitive to variation in input. IA children in both age groups are receiving input that is likely greater in quantity and quality than the general population (due to their high SES environment). However, the IA infants may be immersed in such a rich language environment that their maturational status may be limiting their ability to take advantage of the high quality and quantity of the input they are receiving. Specifically, the IA preschoolers may be more ready to make use of the input because their other cognitive skills (e.g., memory) are more fully developed. They can learn 


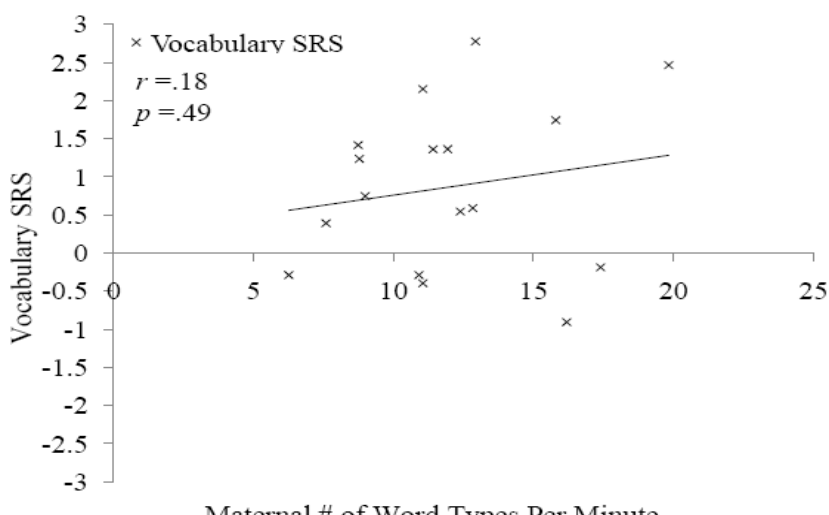

Maternal \# of Word Types Per Minute

Figure 2: IA Infants' Vocabulary SRSs by Diversity of Maternal Input (Experiment 2).



Figure 3: IA Infants' Vocabulary SRSs by Alternative Questions in Maternal Input (Experiment 2).

faster so input is more likely to be a rate-limiting factor. It may also feel more natural to speak more to an older child (IA preschooler) and more input likely results in greater variability in input that the child can exploit. There may be less variation in the input for the IA infants, providing less for the child to exploit.

Contrary to previous studies, we did not find a significant effect of maternal input quantity on vocabulary. However, the raw correlations between input quantity and vocabulary were significant for the IA preschooolers. The correlation likely disappears when put into the regression due to the high correlation between number of words and number of word types, with number of word types soaking up all the variance in children's SRS. This suggests that the amount of input may have an effect, but it is suppressed by effect of the input diversity. Another possible explanation for the discrepancy between the IA children in this study and prior findings is that there is a ceiling effect for the effect of environment. Specifically, there is evidence suggesting that environmental contributions may be greater in low-SES samples where environment is likely to be the limiting factor, and smaller in high-SES samples where it is less likely to be the limiting factor (Turkheimer, Haley,
Waldron, D'Onofrio, \& Gottesman, 2003).

However, there is an important difference between the current study and previous ones. Previous studies have an unavoidable confound of environmental (often indicated by SES) and genetic influences on children's language development. Variation in parental language input may contribute to variability in language development, but biological parents provide their children with both linguistic and genetic input. Thus it is possible that correlations between parental input and child outcomes in previous studies reflect direct effects of shared genes on verbal abilities, and not a direct causal link between input and outcome. So what is the role of genetics in language development?

\section{The Role of Genetics in Language Development}

As part of the Twins' Early Development Study (TEDS) thousands of twins were studied to investigate the roles of environmental and genetic factors in children's language development (Oliver \& Plomin, 2007; Plomin \& Dale, 2000). One motivation for TEDS was a consistent set of findings from adoption and twin studies suggesting a significant effect of genetics on language ability. Although the early findings suggest that nonverbal and verbal abilities have a similar genetic correlation and are moderately correlated with each other (Plomin \& Dale, 2000), later studies suggest a stronger environmental influence (Spinath, Ronald, Harlaar, Price, \& Plomin, 2003). The myriad of studies published on TEDS data also suggest that the relative potency of genetic and environmental influences changes over time (Oliver \& Plomin, 2007).

The genetic confound present in many studies of the effect of input on children's language development was removed in another recent study, which explored effects of teacher input on syntactic development (Huttenlocher, Vasilyeva, Cymerman, \& Levine, 2002). The study measured children's syntactic growth over a school year and found it was predicted by qualitative aspects of their preschool teacher's syntactic input, suggesting a direct effect of input on acquisition. According to the authors, this pattern of findings suggests that observed correlations between language input and output in prior research may reflect a causal role of input in language acquisition. While it is true that these results cannot be explained by genetic factors, the focus was only on syntax. Also, when thinking about the effects of input over time it is likely that any effect of input would be compounded and thus we should expect significant predictive links with overall ability as well.

\section{Conclusions}

Like populations of children learning their first language from birth, maternal input (nurture) significantly correlated with English vocabulary development in IA children. These relations were strong despite the fact that IA children share no genetic influence (nature) with their adoptive parents. This reconciles the gene-environment confound present in previous studies and provides additional support for the role 
of maternal input in children's vocabulary development. In addition, the inclusion of two different age groups provided insight into the contexts in which effects of language input are likely to be largest.

The development of language depends on many things including input, general cognitive skills (e.g., memory), etc. When cognitive skills are well developed and language acquisition is rapid, then the pace of language development is most likely to depend on the variation in input. Thus we see maternal input effects in the preschool-aged IA children even though the amount of (and variation in) input for all children was quite high. In contrast, when the pace of language acquisition is slower because cognitive skills are still developing, then language input may be less likely to be a limiting factor-particularly for children who are in inputrich environments (i.e., IA children).

\section{Acknowledgments}

We would like to thank Abbie Claflin, Nicole Gavel, Ellen Godena, Candice Ishikawa, Corinne Jones, Eva Liggett, Angela Lou, John Ste Marie, Ryan Sykora, Cathy Tillman, and K. Yvonne Woodworth for assistance with data collection and transcription; Katie Felkins for her endless assistance over the years; and the families who participated for their altruism. This project was generously supported by a grant from the NSF (No. 0418423) to the third author.

\section{References}

Caldwell, B., Heider, J., \& Kaplan, B. (1966, September). Home observation for measurement of the environment. Paper presented at the meeting of the American Psychological Association.

Elardo, R., Bradley, R., \& Caldwell, B. (1977). A longitudinal study of the relation of infants' home environments to language development at age three. Child Development, 4, 595-603.

Fenson, L., Marchman, V., Thal, D., Dale, P. S., Bates, E., \& Reznick, J. S. (2006). MacArthur-Bates communicative development inventories (CDIs) (2nd ed.). Baltimore, MD: Brookes Publishing.

Hackman, D. A., \& Farah, M. J. (2009). Socioeconomic status and the developing brain. Trends in Cognitive Sciences, 13(2), 6573.

Hart, B., \& Risley, T. R. (1992). American parenting of languagelearning children: Persisting differences in family--child interactions observed in natural home environments. Developmental Psychology, 28, 1096-1105.

Hart, B., \& Risley, T. R. (1995). Meaningful differences in the everyday experiences of American children. Baltimore, MD: Brookes Publishing.

Hoff-Ginsberg, E. (1986). Function and structure in maternal speech: Their relation to the child's development of syntax. Developmental Psychology, 22, 155-163.

Hoff-Ginsberg, E. (1998). The relation of birth order and socioeconomic status to children's language experience and language development. Applied Psycholinguistics, 19, 603-629.

Hoff, E. (2003a). Causes and consequences of SES-related differences in parent-to-child speech. In M. H. Bornstein \& R. H. Bradley (Eds.), Socioeconomic status, parenting, and child development (pp. 147-160). Mahwah, NJ: Erlbaum.
Hoff, E. (2003b). The specificity of environmental influence: Socioeconomic status affects early vocabulary development via maternal speech. Child Development, 74, 1368-1378.

Hurtado, N., Marchman, V. A., \& Fernald, A. (2008). Does input influence uptake? Links between maternal talk, processing speech and vocabulary size in Spanish-learning children. Developmental Science, 11, F31-F39.

Huttenlocher, J., Haight, W., Bryk, A., Seltzer, M., \& Lyons, T. (1991). Early vocabulary growth: Relation to language input and gender. Developmental Psychology, 27, 236-248.

Huttenlocher, J., Vasilyeva, M., Cymerman, E., \& Levine, S. (2002). Language input and child syntax. Cognitive Psychology, $45,337-374$.

Huttenlocher, J., Vasilyeva, M., Waterfall, H. R., Vevea, J. L., \& Hedges, L. V. (2007). The varieties of speech to young children. Developmental Psychology, 43, 1062-1083.

Kirk, S., McCarthy, J., \& Kirk, W. (1968). Examiner's manual: Illinois test of psycholinguistic abilities (Rev. ed.). Urbana, IL: University of Illinois Press.

MacWhinney, B. (2000). The CHILDES project: Tools for analyzing talk. Mahwah, NJ: Erlbaum.

Oliver, B. R., \& Plomin, R. (2007). Twins' Early Development Study (TEDS): A multivariate, longitudinal genetic investigation of language, cognition and behavior problems from childhood through adolescence. Twin Research and Human Genetics, 10, 96-105.

Plomin, R., \& Dale, P. S. (2000). Genetics and early language development: A UK study of twins. In D. V. M. Bishop \& B. E. Leonard (Eds.), Speech and language impairments in children: Causes, characteristics, intervention and outcome. (pp. 35-51). Hove, UK: Psychology Press.

Snedeker, J., Geren, J., \& Shafto, C. L. (2007). Starting over: International adoption as a natural experiment in language development. Psychological Science, 18, 79-87.

Snedeker, J., Geren, J., \& Shafto, C. L. (in press). Disentangling the effects of cognitive development and linguistic expertise: A longitudinal study of the acquisition of English in internationally-adopted children. Cognitive Psychology.

Spinath, F. M., Ronald, A., Harlaar, N., Price, T. S., \& Plomin, R. (2003). Phenotypic $g$ early in life: On the etiology of general cognitive ability in a large population sample of twin children aged 2 - 4 years. Intelligence, 31, 195-210.

Stromswold, K. (2001). The heritability of language: A review and meta-analysis of twin, adoption and linkage studies. Language, 77, 647-723.

Turkheimer, E., Haley, A., Waldron, M., D'Onofrio, B., \& Gottesman, I. I. (2003). Socioeconomic status modifies heritability of IQ in young children. Psychological Science, 14, 623-628.

Weizman, Z. O., \& Snow, C. E. (2001). Lexical input as related to children's vocabulary acquisition: Effects of sophisticated exposure and support for meaning. Developmental Psychology, 37, 265-279.

Whitehurst, G. J. (1997). Language processes in context: Language learning in children reared in poverty. In L. B. Adamson \& M. A. Romski (Eds.), Research on communication and language disorders: Contribution to theories of language development (pp. 233-266): Brookes Publishing.

Zimmerman, F. J., Gilkerson, J., Richards, J. A., Christakis, D. A., $\mathrm{Xu}$, D., Gray, S., et al. (2009). Teaching by listening: The importance of adult-child conversations to language development. Pediatrics, 124, 342-349. 